Egyptian Journal of Aquatic Biology \& Fisheries

Zoology Department, Faculty of Science,

Ain Shams University, Cairo, Egypt.

ISSN $1110-6131$

Vol. 25(2): 193 - 204 (2021)

www.ejabf.journals.ekb.eg

\title{
Utilization of Different Types of Microalgae to Improve Hatcheries Production of the Sea Cucumber Holothuria scabra Jaeger, 1833 in the Red Sea, KSA.
}

\author{
Mohammed Abdelaty ${ }^{1}$, Lafi Al-Solami ${ }^{1}$, Mamdouh Al-Harbi ${ }^{1}$, \\ Mohamed Abu El-Regal ${ }^{1,2, *}$ \\ ${ }^{1}$ Marine Biology Department, Fuculty of Marine Science, King Abdulaziz University, Jeddah, \\ Kingdom of Saudi Arabia \\ ${ }^{2}$ Marine Science Department, Fuculty of Science, Port Said University, Port Said, Egypt \\ ${ }^{*}$ Corresponding Author: $\underline{m}$ abuelregal@yahoo.com
}

\section{ARTICLE INFO}

Article History:

Received: Feb. 24, 2021

Accepted: March 30, 2021

Online: April 5, 2021

Keywords:

Sea cucumber,

larvae,

settlement,

hatcheries,

microalgae

\section{INTRODUCTION}

This study was conducted to test the effect of different micro-algal food on the development and the survival of the early stages of sea cucumber (Holothuria scabra) in the Red Sea at the Kingdom of Saudi Arabia. Four types of microalgae, Chaetoceros gracilis, Isochrysis galbana and Tetraselmis chuii and Spirulina powder were tested individually and in a mixture. Good positive results were observed with Chaetoceros gracilis, Isochrysis galbana and Tetraselmis chuii, whether singly used or in a mixture . Full larval metamorphosis, from late-auricularia to dololaria, was recorded with the mixture of micro-algae at 96 hours, while Chaetoceros gracilis, Isochrysis galbana and Tetraselmis chuii recorded 90\%, 92\% and 82\%, respectively. After $72 \mathrm{hrs}$, a full larval settlement was recorded with Tetraselmis chuii and the mixture of micro-algae. Whereas, a percentage of 97 and 91 of larval settlement was shown with Isochrysis galbana and Chaetoceros gracilis, respectively. The survival rate of larvae, from the first day of hatching to the juveniles, was $7 \%$ with the mixture of microalgae followed by $4 \%$ with Isochrysis galbana and 2\% for both Tetraselmis chuii and Chaetoceros gracilis. The current study proved that feeding the larvae of sea cucumber on different types of live micro-algae was beneficial to increase the survival rate, and improve the larval metamorphosis and settlement. However, considering the current data, future investigations are required to enrich the existing data with proper information to develop sea cucumber hatcheries.

The sea cucumber Holothuria scabra Jaeger, 1833 has been one of the most important sources of fisheries and national income for many coastal societies for a long time (Hair et al., 2012). Catching sea cucumbers by fishermen has showed depletion of these resources in the coastal fishing grounds, and has recently stretched out to new and deep fishing areas (Toral-Granda et al., 2008). Increasing attention is being paid to the recovery of sea cucumber stocks, especially where this could potentially be helpful for coastal communities with little other fishing livelihoods (Bell et al., 2008; Hair et al., 2016; Purcell et al., 2016). Furthermore, Sea cucumber (Holothuria scabra)is still in the 
preliminary development phase of experiments to determine the farming commercially and specify culture techniques (Toral-Granda $\boldsymbol{e t}$ al., 2008). In aquaculture,the survival rate of sea cucumber larvae is very small compared to other marine species where it reaches less than $1 \%$ at juvenile stage (Purcell et al., 2012). The production of sea cucumber larvae, based on artificial hatchery, helps improve stock and enhances aquaculture sectors (Ito, 2015). The development and simplification of sea cucumbers seed production techniques leads to promoted confidence among stakeholders and the emergence of a new industry on a commercial scale in mariculture (Mills et al., 2012). There are different stages of sea cucumber life cycle in hatcheries until reaching juvenile; Auricularia (living as planktonic and fed on live feed of microalgae), Doliolariae (non feeding stage) that quickly transforms into Pentactulae as soon as conditions are good for settlement (also fed on live feed of microalgae), and lastly transmutes into juveniles that is grown on plates and fed on mix of benthic feed from microalgae and seaweeds (James et al., 1994; Battaglene, 1999; Agudo, 2006; Duy et al., 2016). Micro-algae are used as live food in aquaculture for most life cycle stages of organisms directly, or indirectly as basics of food chains (Brown $\boldsymbol{e t}$ al., 1997). Micro-algae such as Chaetoceros, Isochrysis and other species are very important components and prerequisite for the successful production of sea cucumber larvae (James et al., 1994; Battaglene, 1999; Morgan, 2001; Agudo, 2006; Knauer, 2011; Duy, 2012; Gamboa et al., 2012; Duy et al., 2016). The data recorded on food requirement and adequate diet of sea cucumber larvae culture is very few, a condition that hindered the commercial farming process (Duy et al., 2015). Previous studies have indicated that the larval diet of sea cucumbers consists of a mixture of live micro-algae, whereas it has been recommended for the auricular process (Battaglene, 1999; Agudo, 2006; Duy, 2010). Among the diatom-based single-species diets in larval rearing, Chaetoceros spp have been strongly established as the most acceptable and desirable diet (Knauer, 2011; Duy, 2012; Gamboa et al., 2012). Nevertheless, owing to a lack of understanding the nutritional requirements of Holothurian larvae, the reasons why Chaetoceros spp are the most appropriate and successful micro-algae remain unknown (Duy et al., 2015). In the Red Sea regions, sea cucumber culture operations have newly been conducted upon, adding to the limited knowledge concerning them, and for the sake of the growth of this industry, the development of feeding protocols is extremely necessary. Thus, this work was conducted to test the nutritional efficiency on four microalgae types to determine the best food source during larval stage of sea cucumber Holothuria scabra after hatching until juvenile and support larval settlement and surviva as well.

\section{MATERIALS AND METHODS}

\section{Broodstock collection and spawning}

A total of 20 adult sea cucumber (Holothuria scabra) were collected from AlQunfudhah area, southwest of the Kingdom of Saudi Arabia (19 $19^{\circ} 13^{\prime} 22.9^{\prime \prime} \mathrm{N}, 41^{\circ} 02^{\prime}$ 25.2" E). The sizes of individuals ranged from 500 to 650 grams with an average weight of $579.25 \mathrm{~g}$. Animals were transferred individually to the sea cucumber hatchery of the National Aquaculture Group (NAQUA) in Al-Laith region three days before spawning. They were stocked in $30 \mathrm{C}^{\circ}$ water temperature, and were induced with thermal shock $5 \mathrm{C}^{\circ}$ less for only one hour, followed by a bath of dried micro-algae Spirulina $\left(200 \mathrm{~g} / 1 \mathrm{~m}^{3}\right.$ seawater) for another one hour (Ito, 2015). Spawning occurred in tanks with capacity 
three cubic meters, filled with seawater through one-micron filter bag, and stocking density of seven animals $/ \mathrm{m}^{2}$. The eggs were collected from the spawning tank and transferred to a hatching tank of five cubic meters with stocking density of an egg/ml of seawater. 24 hours after hatching, larvae were transferred to 100L experimental tanks.

\section{Micro-algae}

Three types of live microalgae (Chaetoceros gracilis, Isochrysis galbana and Tetraselmis chuii) were produced in laboratory conditions (in a sterilized room with a temperature of $19^{\circ} \mathrm{c}$, water $\mathrm{pH}$ of 8.1 , and an aeration current (air and $\mathrm{CO}_{2}$ ) in addition to bright illumination). EPIZYM-AGP® product (Epicore, 2015) was used as a growth fertilizer. Dry Spirulina sp powder was used as fourth type of microalgae. The four types of microalgae were tested in concentrations (100\% concentration for each type, mixture of each type $25 \%$ concentrate and mixture of $33 \%$ concentration for only live microalgae). Algal cells were counted daily in the source and inside the tanks before daily feeding and maintaining the required concentration for each species during the experiment. The number of algae cells was increased regularly during the rearing period, according to Ito (2015) protocol.

\section{Rearing of larvae}

The sea cucumber larvae were stored in a phase Auriculares, 24 hours after hatching in 100-liter tanks. The tanks were filled with filtered seawater by micron filter-bag, salinity of 39 PSU, temperature of $29 \mathrm{C}^{\circ}$ and a stocking density of 50 larvae /L. The tanks were distributed randomly concerning each type of algae and concentrations. Almost $40 \%$ of water in the tank was changed daily. Dissolved oxygen concentration $\left(\mathrm{O}_{2}\right)$, temperature, $\mathrm{pH}$ and salinity were measured periodically twice a day. The number of algal cells $/ \mathrm{mL}$ was estimated by triplicate counts for each tank before daily feeding by haemocytometer under the microscope. Larvae were fed by fixed number 25,000 cells $/ \mathrm{ml}$ as daily rations and the numbers of algal cells were increased to 45,000 cells $/ \mathrm{ml}$ as larvae grow. Microscopic examination was conducted every day during experiment to determine larval metamorphosis and feeding conditions. At the end of each stage, the larvae were counted and the number of survivals was determined. Experiment was conducted in triplicate, settlement substrates were added to all tanks when reached $70 \%$ of the doliolariae larval stage. The experiment lasted for 26 days after hatching.

\section{Data analysis:}

One-way ANOVA was used to determine the differences in the effects of various food items, temperatures, and number of days on the settlement, metamorphosis and the survival rates of larvae. Data were arcsine transformed prior to analysis. Two-way ANOVA was used to study the combined effects of temperatures and food concentrations on the rates of metamorphosis, settlement and the survival of larvae. Moreover, three-way ANOVA was used to find the effect of combination of food type, temperature and the number of days on the different rates. Tukey's post-hoc tests were conducted to assess differences between treatments. Multiple regression models were applied using XLSTAT to predict the survival rate as a function of food concentration and temperature. 


\section{RESULTS}

The experiment started with 50 thousand larvae and 20601 larvae were obtained after full transformation of the larvae to the dololaria stage with visible positive results. The quality of the larvae was observed and good behaviour and maximum food for the stomach was seen (Fig. 1).

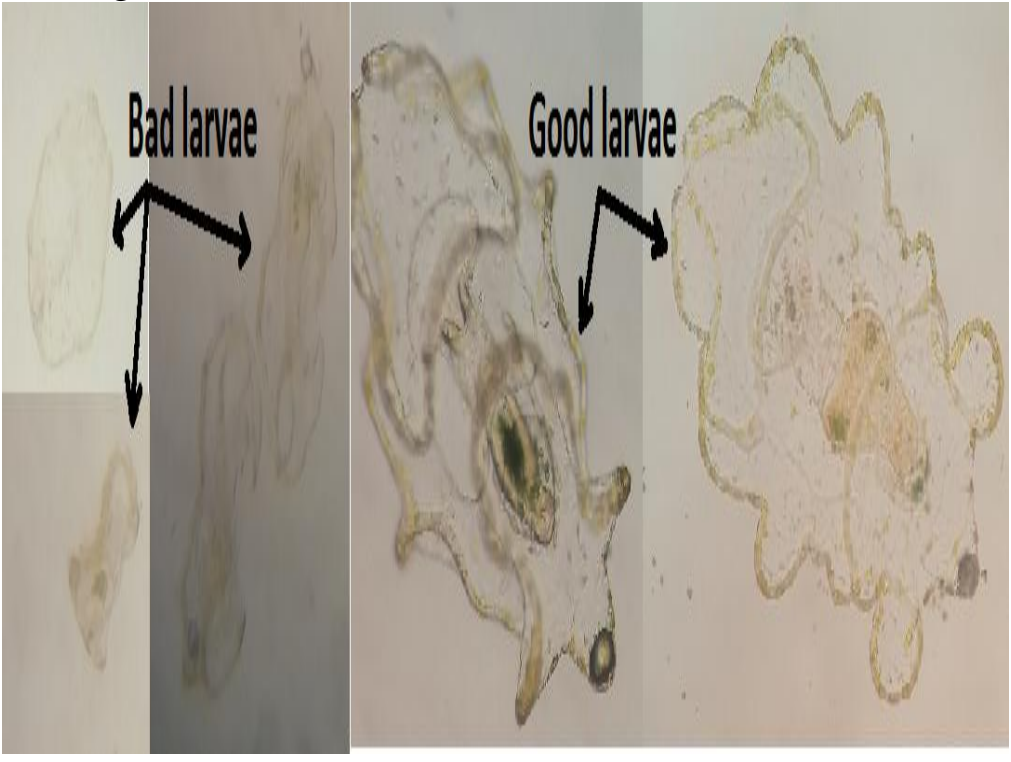

Figure 1. Healthy larvae and poor larvae observed by live micro-algae feeding.

The results of feeding, metamorphosis and survival rates for triplicate all microalgae species used have been recorded as follows:

\section{Microalgae consumption rate}

Feeding started at a rate of 20,000 cells per milliliter on the first day of storage. According to the Ito (2015) protocol, the rates increased steadily to 45,000 during the Auriculares stage. The consumption rates were not steady during the whole experiment period (Table 1). The mixture of the three types of algae tended to have the best rate of consumption among all food items followed by Tetraselmis chuii, then Isochrysis galbana and Chaetoceros gracilis (Figure 2). Due to the larval metamorphosis to the dololaria stage (fasting stage) before settlement, a drop in the consumption rate arose from the tenth day onwards (Table 1). 
Table 1. The food consumption rate (no. algal cells/millilitre) consumed by Auriculares up to the point of dololaria metamorphosis.

\begin{tabular}{lllll}
\hline Time & Chaetoceros gracilis & Isochrysis galbana & Tetraselmis chuii & Mixture \\
\hline Day 1 & $18333 \pm 1178$ & $14166 \pm 1178$ & $19166 \pm 1178$ & $16666 \pm 1178$ \\
Day 2 & $13333 \pm 5137$ & $7500 \pm 4082$ & $15000 \pm 3535$ & 22500 \\
Day 3 & $10000 \pm 4082$ & $9166 \pm 1178$ & $16000 \pm 2483$ & $20833 \pm 1178$ \\
Day 4 & $13333 \pm 2357$ & $8333 \pm 3118$ & $16666 \pm 1178$ & 20000 \\
Day 5 & $17500 \pm 2041$ & $19166 \pm 3118$ & $25833 \pm 1178$ & $30000 \pm 2041$ \\
Day 6 & $23333 \pm 3118$ & $34166 \pm 1178$ & $32500 \pm 2041$ & $33333 \pm 1178$ \\
Day 7 & $34166 \pm 2357$ & $40833 \pm 1178$ & $39166 \pm 1178$ & $36666 \pm 1178$ \\
Day 8 & $40000 \pm 2041$ & $39166 \pm 1178$ & $29166 \pm 3118$ & $35833 \pm 3118$ \\
Day 9 & $41666 \pm 1178$ & $40000 \pm 2041$ & 37500 & $31666 \pm 1178$ \\
Day 10 & $39166 \pm 1178$ & $35000 \pm 2041$ & $35833 \pm 1178$ & $26666 \pm 1178$ \\
Day 11 & $33333 \pm 1178$ & $30833 \pm 1178$ & $33333 \pm 1178$ & 25000
\end{tabular}

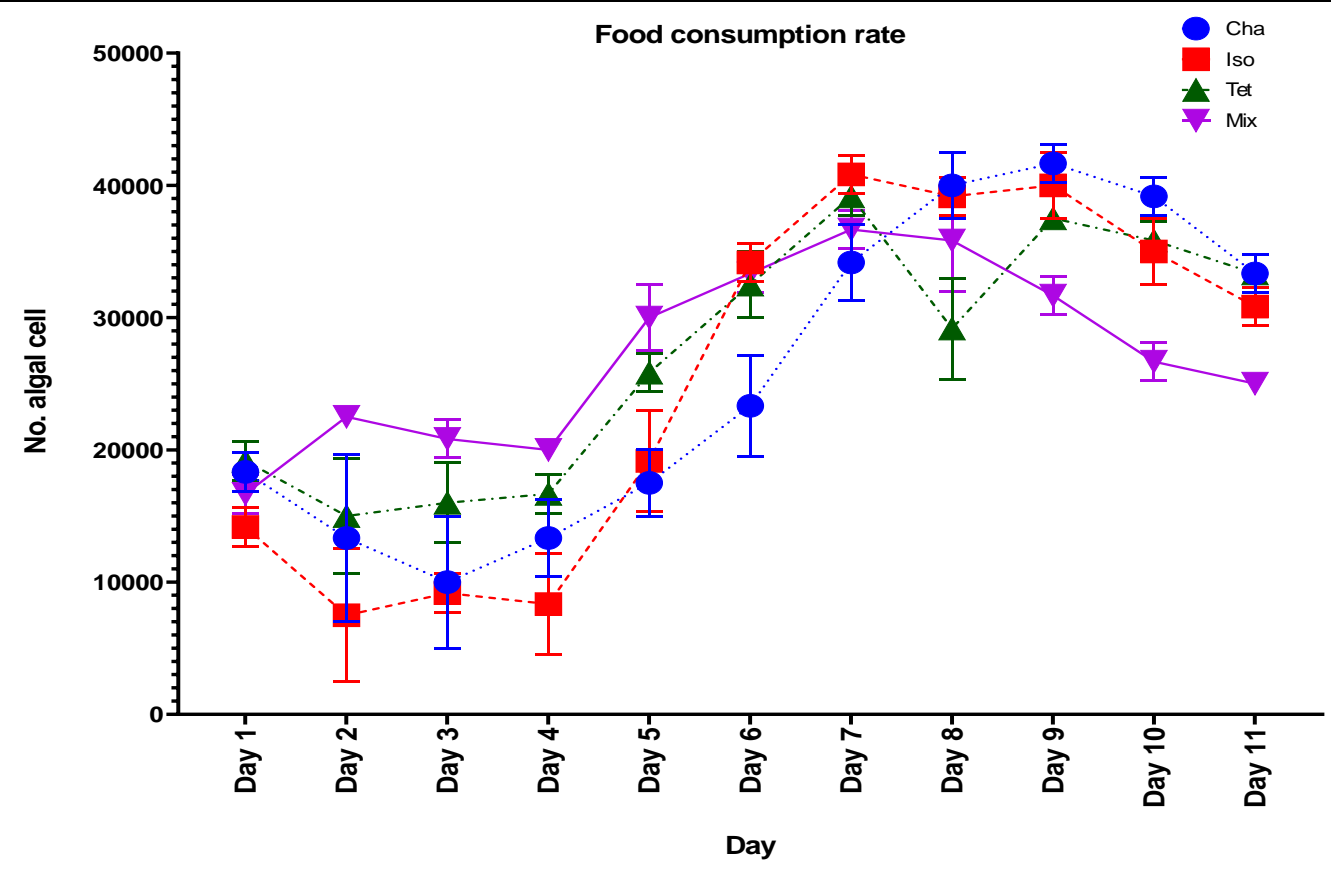

Figure 2. Numbers of algal cells in millilitres are consumed from experimental animals during the Auriculares stage.

\section{Metamorphoses}

Metamorphoses of late-auricularia to dololaria showed noticeable differences with the types of micro-algae utilized (Table 2). During the first 24 hours the complete dololaria recorded $17 \%$ of metamorphosis with the mixture of live micro-algae followed by Isochrysis galbana (15\%), Chaetoceros gracilis (8\%) and Tetraselmis chuii (6\%) (Fig.3). 
While the metamorphosis recorded significant changes after 48 hours with the mixture of live micro-algae (67\%), Isochrysis galbana (21\%), Chaetoceros gracilis (11\%) and Tetraselmis chuii (15\%). Furthermore, after 72 hours, metamorphosis recorded $94 \%$ with mixture of live micro-algae, and 76\%, 57\%, 48\% for Isochrysis galbana, Chaetoceros gracilis and Tetraselmis chuii, respectively. All dololaria have been transformed after 96 hrs with the mixture of live micro-algae. On the other hand, Isochrysis galbana, Chaetoceros gracilis and Tetraselmis chuii recorded 92, 90, and 89\% within the same time, respectively. The analysis of variance (ANOVA) showed that the rate of metamorphosis varied significantly between different food items $(\mathrm{F}=16.29, \mathrm{P}<0.05)$ and number of days $(\mathrm{F}=5.96, \mathrm{P}<0.05)$. Two-way ANOVA indicated that the combination of food and temperature and combination of food and number of days have a significant effect on the rate of metamorphosis of late-auricularia to dololaria $(\mathrm{F}=2.80 \mathrm{P}<0.05$ and $\mathrm{F}=69.003 \mathrm{P}<0.005$, respectively). On the other hand, there was an insignificant difference between the effect of combination of both temperature and number of days $(\mathrm{F}=$ $1.83 \mathrm{P}>0.05)$.

Correlation analysis showed a significant negative correlation between temperature and metamorphosis rate of the auricularia to dololaria $\left(R=-0.7, R^{2}=0.4\right)$

Table 2. Percentage of metamorphosis from late-auricularia to complete dololaria fed by micro-algae. Metamorphosis of larvae was determined on day 9, 10,11, 12 and 13 after hatching.

\begin{tabular}{ccccc}
\hline Time & \multicolumn{3}{c}{ \% of metamorphosis to complete dololaria } \\
\cline { 2 - 5 } & $\begin{array}{c}\text { Chaetoceros } \\
\text { gracilis }\end{array}$ & $\begin{array}{c}\text { Isochrysis } \\
\text { galbana }\end{array}$ & Tetraselmis chuii & $\begin{array}{c}\text { Mixture 33\% of } \\
\text { each micro- } \\
\text { algae }\end{array}$ \\
\hline $\mathbf{2 4}$ hours & $8 \pm 9$ & $15 \pm 6$ & $6 \pm 2$ & $17 \pm 4$ \\
$\mathbf{4 8}$ hours & $11 \pm 2$ & $21 \pm 6$ & $15 \pm 3$ & $67 \pm 9$ \\
$\mathbf{7 2}$ hours & $57 \pm 8$ & $76 \pm 5$ & $48 \pm 9$ & $94 \pm 1$ \\
$\mathbf{9 6}$ hours & $90 \pm 4$ & $92 \pm 2$ & $82 \pm 6$ & 100 \\
\hline
\end{tabular}




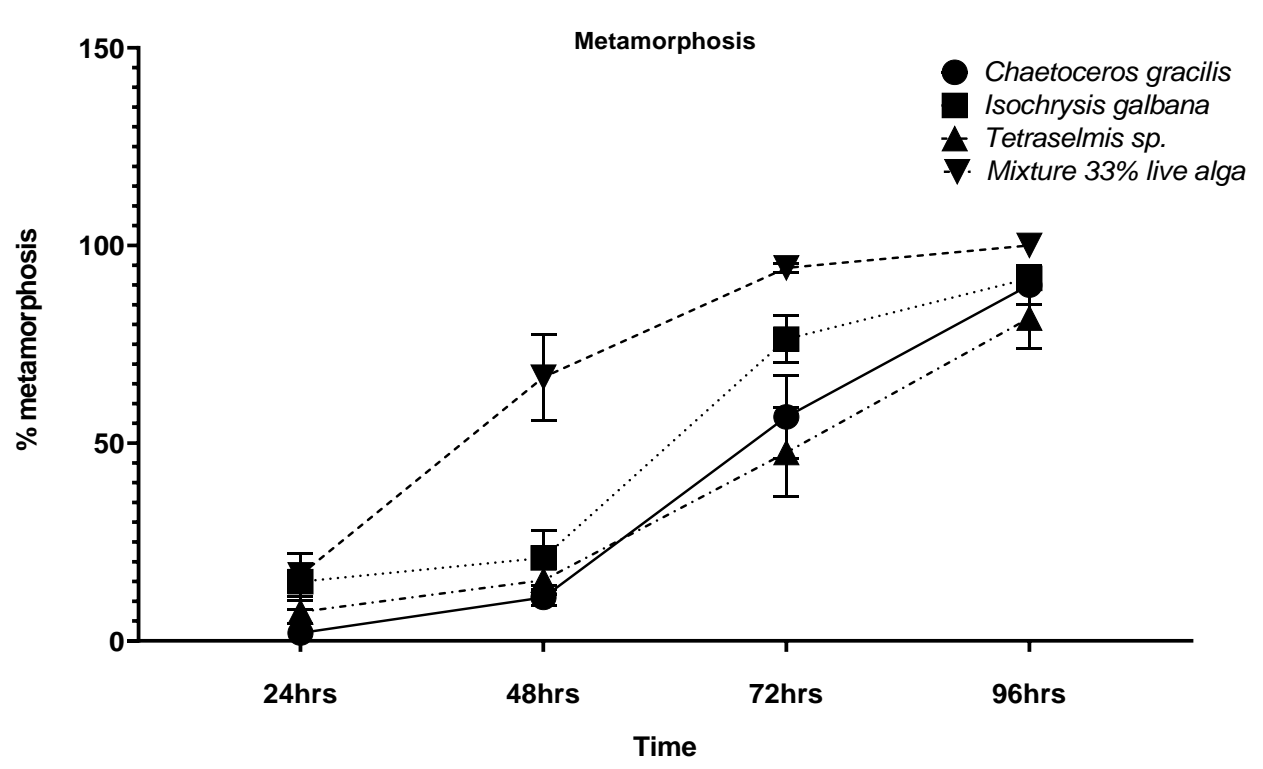

Figure 3. Ratio of larvae metamorphosis from late auricularia to dololaria.

\section{Settlement}

At the first day of settlement, the settlement rates of dololaria were $41 \%, 44 \%, 62 \%$ and $39 \%$ for Chaetoceros gracilis, Isochrysis galbana, Tetraselmis chuii and mixture of live algae respectively, (Table 3 and figure 4). At the second day, dololaria settlement recorded $81 \%, 84 \%, 83 \%$ and $89 \%$ for Chaetoceros gracilis, Isochrysis galbana, Tetraselmis chuii and mixture of live algae, respectively. On the other hand, larval settlement recorded $91 \%, 97 \%, 100 \%$ and $100 \%$ at the third day respectively. Settlement of all larvae was $100 \%$ complete at the fourth day.

The analysis of variance (ANOVA) showed that the rate of metamorphosis varied significantly between different food items $(\mathrm{F}=43.05, \mathrm{P}<0.05)$, temperature $(\mathrm{F}=2.34, \mathrm{P}$ $<0.05)$. Whereas, the effect of the number of days was insignificantly different $(\mathrm{F}=2.26$, $\mathrm{P}>0.05)$. Two-way ANOVA indicated that the effect of combination of food and temperature, and the combination of food and the number of days and the effect of the combination of both temperature and number of days were insignificant. ( $\mathrm{F}=0.5 \mathrm{P}>0.05$ and $\mathrm{F}=1.9 \mathrm{P}<0.005$, respectively). On the other hand, there was a significant difference between the effect of the combination of food and number of days $(\mathrm{F}=1.89 \mathrm{P}<0.05)$.

Table 3. Percentage of larvae settlement fed different micro-algae throughout the experiment. Settlement of larvae was determined on day 13, 14, 15 and 16 after hatching.

\begin{tabular}{ccccc}
\hline \multirow{2}{*}{ Time } & \multicolumn{4}{c}{ \% of larvae settlement } \\
\cline { 2 - 5 } & $\begin{array}{c}\text { Chaetoceros } \\
\text { gracilis }\end{array}$ & $\begin{array}{c}\text { Isochrysis } \\
\text { galbana }\end{array}$ & Tetraselmis chuii & $\begin{array}{c}\text { Mixture 33\% } \\
\text { live algae }\end{array}$ \\
\hline 24 hours & $41 \pm 3$ & $44 \pm 16$ & $62 \pm 4$ & $39 \pm 18$ \\
48 hours & $81 \pm 3$ & $84 \pm 5$ & $83 \pm 10$ & $89 \pm 2$ \\
72 hours & $91 \pm 1$ & $97 \pm 4$ & 100 & 100 \\
\hline
\end{tabular}




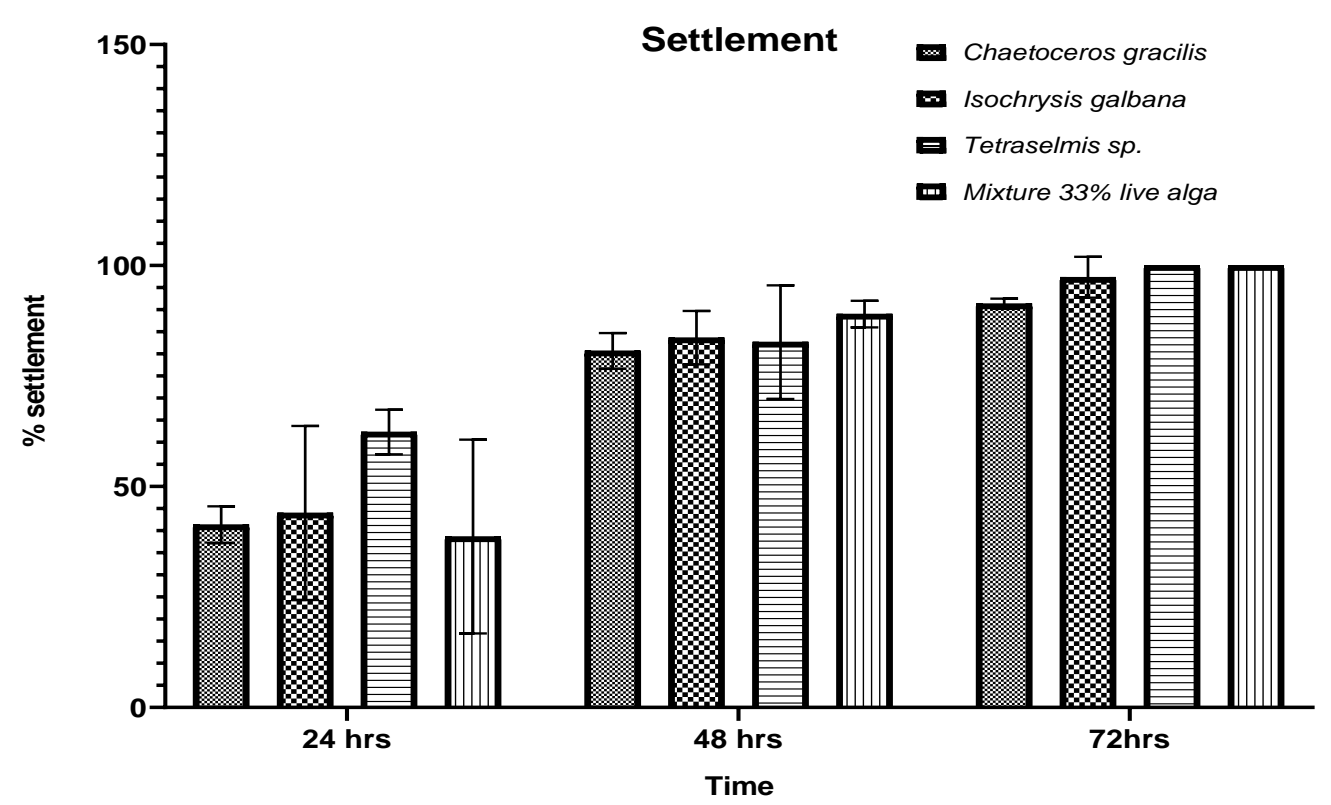

Figure 4. Percentage of settlement of dololaria stage until settlement completion.

\section{Survival rate}

Survival rate of sea cucumber larvae has varied with different feeding types of microalgae and different larval stages (Table 4 and Figure 5).

The total survival percentages recorded at the larval stage late-auricularia were 59\%, $56 \%, 49 \%$ and $70 \%$ for Chaetoceros gracilis, Isochrysis galbana, Tetraselmis chuii and mixture of live algae, respectively. However, these rates varied at complete dololaria larval stage where they recorded 37\%, 35\%, 30\% and 35\% for Chaetoceros gracilis, Isochrysis galbana, Tetraselmis chuii and mixture of live algae, respectively. Furthermore, the total survival rate at juvenile was $2 \%, 4 \%, 2 \%$ and $7 \%$, respectively with the same types of micro-algae at the end of experiment after 26 days of hatch. In comparison, the tests showed negative findings with separate spirulina powder and a micro-algae mixture of $25 \%$ and the same results with triplicates. Furthermore, in day 12 of the experiment, animals began to shrink and mortality rates increased until it reported 100 percent for both separate spirulina powder and micro-algae mixture 25 percent.

The analysis of variance (ANOVA) showed that the rate of metamorphosis varied significantly between different food items $(\mathrm{F}=4.69, \mathrm{P}<0.05)$, temperature $(\mathrm{F}=4.96, \mathrm{P}$ $<0.05)$, and the number of days $(\mathrm{F}=51.79, \mathrm{P}<0.05)$. Two-way ANOVA indicated that the effect of combination of food and temperature and combination of food and number of days $(\mathrm{F}=1.19 \mathrm{P}<0.05$ and $\mathrm{F}=7.44 \mathrm{P}<0.005$, respectively). On the other hand, there was a significant difference between the effect of the combination of temperature and the number of days $(\mathrm{F}=0.74 \mathrm{P}>0.05)$. 
Table 4. The number of survived sea cucumber larvae fed different micro-algae throughout the experiment. Survival of larvae was estimated on day 6, 12 and 27 after hatching.

\begin{tabular}{lccc}
\hline \multicolumn{1}{c}{ Feeding types } & $\begin{array}{c}\text { At late- } \\
\text { auricularia }\end{array}$ & $\begin{array}{c}\text { At complete } \\
\text { dololaria }\end{array}$ & At juveniles \\
\hline $\begin{array}{l}\text { Chaetoceros gracilis } \\
\text { Isochrysis galbana }\end{array}$ & $2933 \pm 531$ & $1833 \pm 287$ & $91 \pm 12$ \\
$\begin{array}{l}\text { Tetraselmis } \text { chuii } \\
\text { Mixture 33\% of live }\end{array}$ & $2460 \pm 779$ & $1767 \pm 205$ & $211 \pm 56$ \\
algae & $3500 \pm 294$ & $1500 \pm 283$ & $124 \pm 9$ \\
\hline
\end{tabular}

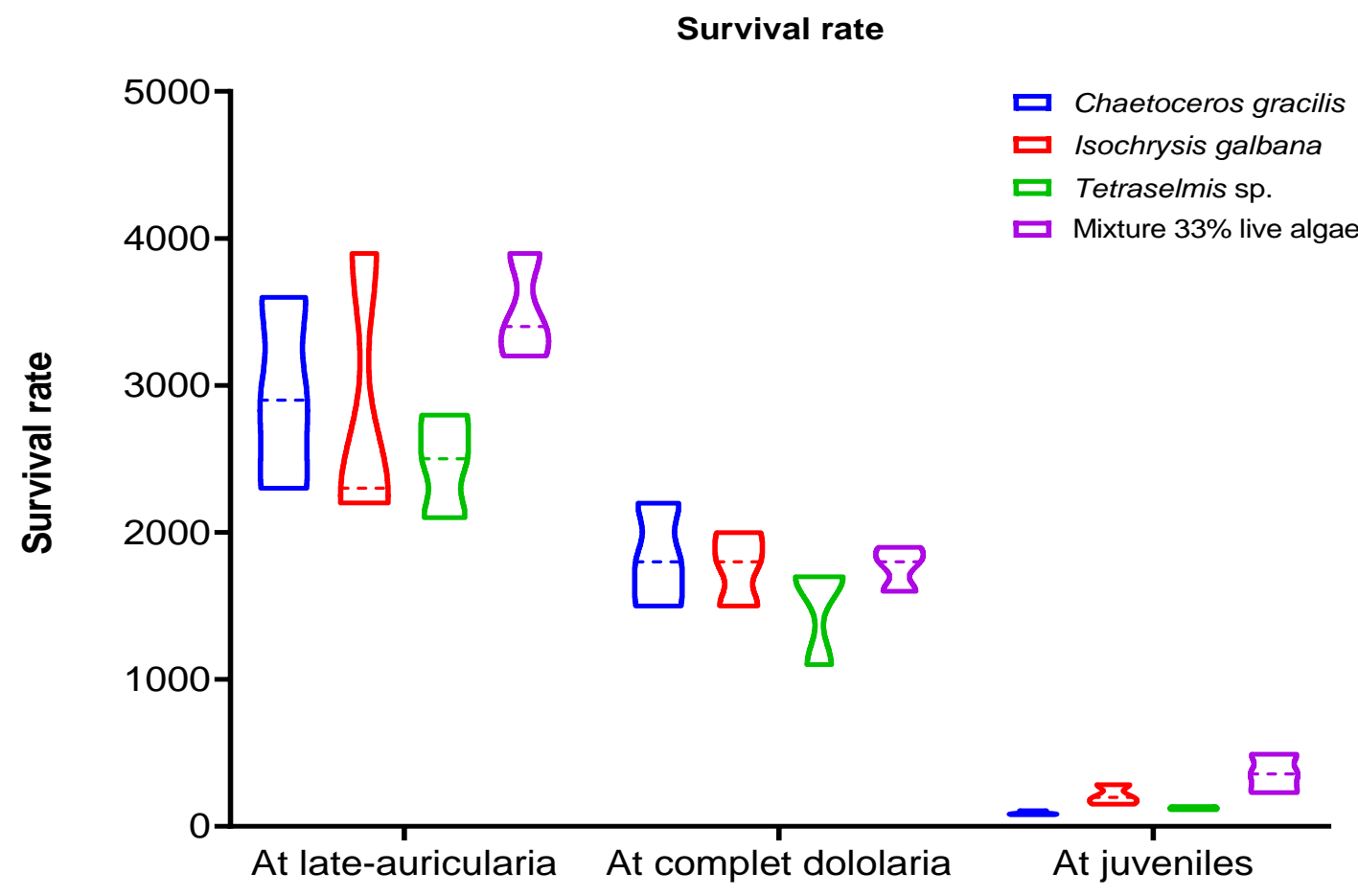

\section{Stage}

Figure 5. Box and violin showing the survival rate of sea cucumber larvae fed on different micro-algae.

\section{DISCUSSION}

This study revealed the importance of live micro-algae for sea cucumber hatcheries to improve the quality and survival ratios of the larvae in the Red Sea region. In addition, low-cost live species of microalgae were used, which are typical in most mariculture hatcheries. The experiment is relatively straightforward and well applicable to the provisional evaluation of various diets for live micro-algae, and this was the technique used in the present research. The current findings indicate that live micro-algae were able to sustain large-scale sea cucumber hatchery development in the Red Sea region with a low-resource hatchery. The results presented that live micro-algae supported sea 
cucumber larvae performance with three micro-algae fed either singly or in a mixture. Moreover, the results confirmed on different rates of survival, larvae transformation and settlement. Substantial changes appeared in survival rates and larvae quality compared to previous studies (Purcell et al., 2012; Duy et al., 2016). The types of micro-algae used in this study were chosen based on availability in most aquaculture hatcheries and previous studies that have proven ease of digestion by sea cucumber larvae (Purcell et al., 2012; Duy et al., 2015; Duy et al., 2016). Metamorphosis showed a noticeable difference where completed to dololaria after four days with mixture of live micro-algae but with other microalgae, it lasted for five days. Compared to other studies metamorphosis reported the whole transition from late-auricularia to complete dololaria that took four days before settlement (Duy et al., 2016). Furthermore, larval settlement record completely settled within 72 hours with Tetraselmis chuii and mixture of live algae, but it took 96 hours with Chaetoceros gracilis and Isochrysis galbana. On the other hand, it was recorded in previous studies that settlement takes place in 72 hours with the best conditions and a little stay more than 96 hours when the appropriate substrate is not available (Mercier et al., 2000). The larval response to food abundance results in an increased likelihood of survival, either in achieving larval metamorphosed competence or in larvae settlement (Morgan, 2008). Results also indicated good survival rate with mixture $33 \%$ of live micro-algae which recorded $7 \%$ at juvenile on age 26 days of hatch as maximum survival in the present study. But survivals recorded $2 \%$ as minimum ratio with both types Chaetoceros gracilis and Tetraselmis chuil, and the ratio varied with Isochrysis galbana recording $4 \%$ as final survival. On the other hand, these results have converged with previous study, which was conducted on artificial micro-algae and recorded 6.7\% with Isochrysis1800® (Duy et al., 2016).

The current research revealed marked variations in survival rates, metamorphosis and settlement times, and when used in mega-scale culture structures, these variations were likely to result in many outcomes. Therefore, further experiments are recommended as a guide to the adoption of micro-algae types on large-scale sea cucumber hatchery culture for an optimized implementation of the findings of this analysis. The preference for the rate of food intake was also indicated, and this was reflected in larval growth and metamorphosis performance. Hence, it is also recommended not to focus exclusively on one species of living microalgae in the feeding process in general.

\section{CONCLUSION}

The study showed that feeding the larvae of sea cucumber on live micro-algae was useful to improve the larval metamorphosis and settlement and increase its survival rate, especially with a mixture of the three types used in this experiment. In addition, the preference of Holothuria scabra larvae in feeding types was clarified, and its reflection on the growth performance was observed. However, considering the current data, more future studies are recommended to enrich the existing data with information that would achieve the development of sea cucumber hatcheries. 


\section{REFERENCES}

Agudo, N. (2006). Sandfish Hatchery Techniques. Australian Centre for International Agricultural Research. Secretariat of the Pacific Community and World Fish Center, Noumea, New Caledonia, 45pp

Battaglene, S.C. (1999). Culture of tropical sea cucumbers for stock restoration and enhancement. Naga. Manila, 22(4): 4-11.

Battaglene, S.C.; Seymour, J.E. and Ramofafia, C. (1999). Survival and growth of cultured juvenile sea cucumbers, Holothuria scabra. Aquaculture, 178 (3-4): 293-322.

Bell, J.D.; Purcell, S.W. and Nash, W.J. (2008). Restoring small-scale fisheries for tropical sea cucumbers. Ocean \& Coast Manage, (5): 589-593.

Brown, M.R; Jeffrey, S.W.; Volkman, J.K. and Dunstan, G.A. (1997). Nutritional properties of microalgae for mariculture. CSIRO Division of marine research: Hobart, Australia. Aquaculture, 151: 315-331.

Duy, N.D.Q. (2010). Seed production of sandfish (Holothuria scabra) in Vietnam. Southeast Asian Fisheries Development Center (SEAFDEC), Iloilo, Philippines, $12 \mathrm{pp}$.

Duy, N.D.Q. (2012). Large-scale sandfish production from pond culture in Vietnam. In: Hair, C.A., Pickering, T.D., Mills, D.J. (Eds.), and Asia-Pacific Tropical Sea Cucumber Aquaculture. ACIAR Proceedings, 136: 34-39.

Duy, N.D.Q.; Pirozzi, I. and Southgate, P.C. (2015). Ingestion and digestion of live micro-algae and micro-algae concentrates by sandfish, Holothuria scabra, larvae. Aquaculture, 448: 256-261.

Duy, D.Q.N; Francis, D.S.; Pirozzi, I. and Southgate, P.C. (2016). Use of micro-algae concentrates for hatchery culture of sandfish, Holothuria scabra. Aquaculture, 464: 145-152.

Epicore BioNetworks Inc. (2015). EPIZYM-AGP® Complete Algae Growth Media. http://epicorebionetworks.com/assets/epizym-agpc.pdf.

Gamboa, R.U.; Aurelio, R.A.; Ganad, D.A.; Concepcion, L.B. and Abreo, N.A.S. (2012). Small-scale hatcheries and simple technologies for sandfish (Holothuria scabra) production. In: Hair, C.A., Pickering, T.D., Mills, D.J. (Eds.), Asia-Pacific Tropical Sea Cucumber Aquaculture ACIAR Proceedings Vol. 136. Australian Centre for International Agricultural Research, Canberra, 63-74.

Hair, C.A.; Pickering, T.D. and Mills, D.J. (eds) (2012). Asia-Pacific tropical sea cucumber aquaculture. Proceedings of an international symposium held in 
Noumea, New Caledonia. ACIAR Proceedings No. 136. Australian Centre for International Agricultural Research: Canberra, 209 pp.

Hair, C.; Foale, S.; Kinch, J.; Yaman, L. and Southgate, P.C. (2016). Beyond boom, bust and ban: the sandfish (Holothuria scabra) fishery in the Tigak Islands: Papua New Guinea. Reg. Stud. Mar. Sci., 5: 69-79.

Ito M. (2015). Hatchery Manual for Sea Cucumber Aquaculture in the U.S. Affiliated Pacific Islands. CTSA Publication \#163. http://www.ctsa.org/files/publications/SeaCucumberHatcheryManual.pdf .

James, D.B.; Gandhi, A.D.; Palaniswamy, N. and Rodrigo, J.X. (1994). Hatchery techniques and culture of the sea-cucumber Holothuria scabra. Special Publication. Central Marine Fisheries Research Institute, Cochin, India, 57pp

Knauer, J. (2011). Growth and survival of larval sandfish, Holothuria scabra (Echinodermata: Holothuroidea), fed different micro-algae. J. World Aquaculture. Soc., 42 (6): 880-887.

Mills, D.J.; Duy, N.D.Q.; Juinio-Menez, M.A.; Raison, C.M. and Zarate, J.M. (2012). Overview of sea cucumber aquaculture and sea-ranching research in the South-East Asian region. In: Hair, C.A., Pickering, T.D., Mills, D.J. (Eds.), Asia-Pacific Tropical Sea Cucumber Aquaculture ACIAR Proceedings Vol. 136. Australian Centre for International Agricultural Research, Canberra, 2231.

Morgan, A.D. (2001). The effect of food availability on early growth, development and survival of the sea cucumber Holothuria scabra (Echinodermata: Holothuroidea). SPC Beche-de-mer Information Bulletin, 14: 6-12.

Morgan, A.D. (2008). The effect of food availability on phenotypic plasticity in larvae of the temperate sea cucumber Australostichopus mollis. Journal of Experimental Marine Biology and Ecology, 363: 89-95.

Purcell, S.W.; Hair, C.A. and Mills, D.J. (2012). Sea cucumber culture, farming and sea ranching in the tropics: Progress, problems and opportunities. Aquaculture, 368-369: 68-81.

Purcell, S.W.; Ngaluafe, P.; Foale, S.J.; Cocks, N.; Cullis, B.R. and Lalavanua, W. (2016). Multiple factors affect socioeconomics and wellbeing of artisanal sea cucumber fishers. PLoS One 11(12): e0165633. https://doi.org/10.1371/journal.pone.0165633

Toral-Granda, V.; Lovatelli, A. and Vasconcellos, M. (eds) (2008). Sea cucumbers. A global review of fisheries and trade. FAO Fisheries and Aquaculture Technical Paper. No. 516. Rome, FAO. 317pp. 